\title{
Knowledge, beliefs and pedagogy: how the nature of science should inform the aims of science education (and not just when teaching evolution)
}

\author{
Keith S. Taber ${ }^{1}$
}

Received: 1 October 2015/Accepted: 31 October 2015/Published online: 30 December 2016

(C) The Author(s) 2016. This article is published with open access at Springerlink.com

\begin{abstract}
Lisa Borgerding's work highlights how students can understand evolution without necessarily committing to it, and how learners may come to see it as one available way of thinking amongst others. This is presented as something that should be considered a successful outcome when teaching about material that many students may find incompatible with their personal worldviews. These findings derive from work exploring a cause célèbre of the science education community - the teaching of natural selection in cultural contexts where learners feel they have strong reasons for rejecting evolutionary ideas. Accepting that students may understand but not commit to scientific ideas that are (from some cultural perspectives) controversial may easily be considered as a form of compromise position when teaching canonical science prescribed in curriculum but resisted by learners. Yet if we take scholarship on the nature of science seriously, and wish to reflect the nature of scientific knowledge in science teaching, then the aim of science education should always be to facilitate understanding of, yet to avoid belief in, the ideas taught in science lessons. The philosophy of science suggests that scientific knowledge needs to be understood as theoretical in nature, as conjectural and provisional; and the history of science warns of the risks of strongly committing to any particular conceptualisation as a final account of some feature of nature. Research into student thinking and learning in science suggests that learning science is often a matter of coming to understand a new
\end{abstract}

Lead Editors: L. Avery and D. E. Long.

This forum contribution addresses issues raised in Lisa Borgerding's paper entitled: High school biology evolution learning experiences in a rural context: A case of and for cultural border crossing. doi:10.1007/ s11422-016-9758-0.

This paper is part of the special issue Cultural Studies of Rural Science Education.

Keith S. Taber

kst24@cam.ac.uk

1 Science Education Centre, University of Cambridge Faculty of Education, 184 Hills Road,

Cambridge CB2 8PQ, England, UK 
viable way of thinking about a topic to complement established ways of thinking. Science teaching should then seek to have students appreciate scientific ideas as viable ways of making sense of the currently available empirical evidence, but should not be about persuading students of the truth of any particular scientific account.

Keywords Beliefs in science $\cdot$ Cultural border-crossing - Scientific knowledge $\cdot$ Teacher as intellectual tour guide - Teaching evolution

Lisa A. Borgerding's paper (present issue) is of considerable interest to the science education community because of the continuing debate within science education on how to respond to the difficulties of teaching natural selection and evolutionary ideas in contexts where students may be resistant to accepting such ideas for cultural reasons-as for example when they consider such ideas are contrary to their own, and their family and community's, religious commitments. To the extent that the science education community can be considered to have a unified position, there is considerable consensus on the need to teach evolutionary theory regardless of the response among learners: yet there is less agreement on the extent to which, and how, learners' own ideas and beliefs should be taken into account. This is an important issue because of the centrality of natural selection to modern biology, and the active and organised opposition to the teaching of evolution in many parts of the world. In the present article I will argue that whilst this is a live debate in relation to evolution and a few other topics (the origin of the universe, for example), the issues raised are more fundamental and concern the aims of science education more generally.

The argument to be made here concerns the nature of science and the kinds of knowledge it can lead to, and the implications this has for the purpose of science education. In brief, the argument to be made is that science education should aim for understanding of scientific ideas, but not for belief in those ideas. To be clear, the argument is not just that science education should not intend to bring about belief in scientific ideas, but rather that good science teaching discourages belief in the scientific ideas being taught. I suspect that many readers (though perhaps not all) will be persuaded of the reasonableness of this position-but unfortunately we have good reason to think that actively teaching to avoid students believing in scientific ideas may itself often be challenging.

\section{The case of teaching evolution}

It is widely accepted that evolution is a key topic in modern biology, and that indeed that natural selection provides a perspective that is infused into virtually all aspects of the life sciences (Dobzhansky 1973). Scientific societies and organisations around the world have stressed the importance of including teaching of evolution in school and college biology curricula (e.g., National Science Teachers Association 2013) - as in the United States context where Borgerding carried out her study and where she reports how curriculum documents emphasise "evolution as an overarching scientific concept holding a high status within the scientific community". However natural selection and its implications seem counter-intuitive to many people, and moreover are actually found objectionable to those from some cultural backgrounds. Notions that human beings evolved from very different kinds of life-forms; that there is no fundamental biological difference between humans and other species; and indeed that if one was able to trace the lineage of any person alive today 
back through time one would reach a point where it was no longer clear if their ancestors should be considered human (i.e., that there would likely be many not-clearly-human generations falling between generations that would generally be agreed to be clearly human, and considerably earlier generations that would generally be clearly agreed to not be human), seem to insult the intelligence and/or the sensitivities of many learners.

There are two sets of issues at work here. For scientists and science teachers long familiar with the theory of natural selection it often provides an apparently simple (perhaps even seemingly obvious) and rational framework for thinking about life on earth that is used as a lens for examining biological topics. Indeed, it may be a conceptual 'lens' applied with regularity, thus reinforcing commitment to the value-and perhaps even the 'truth' - of the theory. Yet understanding natural selection actually requires coordinating a range of distinct ideas (variation, inheritance, geographic separation, etc.) into a coherent conceptual scheme (Taber 2009, pp. 286-288): something which many school age (and even college level) students find challenging. Like many ideas that seem obvious once we 'get' them, natural selection is not something most people come to understand readily.

Teaching evolution, then, involves the kind of challenge that is familiar in teaching many conceptual topics in science education. In a similar way, the Newtonian idea that objects continue to move with constant velocity when not acted upon by a force is counterintuitive to most people. The periodic table of elements provides another example of an intellectual construction (like natural selection) which offers a valuable framework for thinking about (and organising) ideas across a whole science-in this case chemistry rather than biology_but which when first perceived at the student's 'resolution' (i.e. from the perspective of a novice) is too complex to be fully appreciated by most learners without extended effort. Often a good deal of hard work is involved in mastering the scientific ideas which-once we have mastered them-can be so productive in supporting further thinking.

Newtonian mechanics and periodicity in elemental properties may challenge some learners for whom they do not make sense and so seem to represent a huge mental effort (rather than offering an obvious promise of intellectual economy), but few students are likely to find these ideas objectionable or personally insulting. Evolution, however, is considered by many people in some cultures as an offensive ideology (Morris 2000). As Glen Aikenhead (1996) has pointed out, the science curriculum may offer much that seems alien to some students-so learners from some indigenous communities may find aspects of Western science education content and practices to be somewhat at odds with the worldview they have developed from within their own culture. Ironically (given the context of the discussion here), one aspect of the Western scientific culture which learners from some indigenous cultures find problematic is the treatment of non-human animals as classroom exhibits and subjects for laboratory procedures (Allen and Crawley 1998) in a way that implies humanity is on a very different footing (enquirers, controllers) to the rest of the natural world (subjects of enquiry and control). A holistic mindset about nature that requires giving a high degree of respect to members of other species that share our world may make it difficult to appreciate the analytical, reductionist stance of some traditional school science.

\section{Learning science as cultural border-crossing}

In her paper, Borgerding adopts Aikenhead's metaphor of cultural border-crossing with its implication that the science classroom, and its particular norms, terminology, and values, may seem a foreign place to many students, such that entering is akin to visiting another 
culturally distinct country. In Borgerding's study this refers in particular to the acceptance and championing of natural selection, and the 'fact' of evolution in general. Evolutionary ideas are found objectionable by many people in some countries which are otherwise largely supportive of Western Science-including large parts of the United States (Long 2011) where Borgerding carried out her study. For some students, evolution is seen as an atheistic notion which threatens their religious faith, cherished core personal beliefs, and the norms that regulate their community lives. Consequently, even when the teaching of evolution is officially considered part of the core curriculum, it may be resisted, truncated, omitted, or subverted. It is easy to understand why teachers would not wish to alienate their students and the wider community by teaching something most of the local population may consider objectionable - and which sometimes they reject personally themselves.

Arguments within the educational community have concerned how science educators should respond to this resistance (Reiss 2008). Should teachers seek to set out the clear superiority of the evolutionary perspective, its strong evidence base, its extensive applicability in biology, and so forth, compared with the less scientifically defendable views of learners? This after all is how science teachers often proceed when we discover students have 'misconceptions': ideas at odds with target knowledge in the curriculum that need to be challenged to bring about desired conceptual change. Yet this strategy is not always effectively applied even in less contentious topics (Taber 2009). Students' ideas may be well established in their thinking, and when learners' alternative (from the scientific perspective) conceptions have currency in the life-world they are often reinforced by everyday interactions as part of the social milieu (Solomon 1992).

Sometimes even the most fecund scientific ideas may not be persuasive to those who are well versed in alternative ways of thinking, unless there is a considerable period of immersion and extensive experience of application of the new ways of making sense-as seen with Joseph Priestley's failure to adopt Antoine Lavoisier's ideas about combustion (Thagard 1992). In discussing his model of paradigm shifts in the history of science Thomas Kuhn (1996, p. 151) drew upon a quotation from Max Planck to the effect that new ideas in science triumph not when scientists who held a previous orthodoxy were persuaded, but rather when they die leaving a new generation who have been inducted into science on the basis of the successive theoretical framework.

Persuading students to change their minds about a well-established way of thinking about an aspect of the natural world can often be a slow process even when there is nothing more at stake than a way of conceptualising how forces relate to motion or how to understand combustion. Expecting students to reject core personal commitments about the world that people have historically been prepared to go to the stake for is asking a great deal more. In the context of some United States communities accepting evolution is equated with rejecting scripture considered to be the Word of God, and so to be going against God and risking eternal damnation — as well as being seen to go against the beliefs and values of family, friends and community. When respected authority figures in the community reinforce a belief that accepting such ideas as recent creation (recent as in of the order of the last 10,000 years: so called Young Earth Creationism), special creation of different species, and the fall (i.e. the entry of sin into the world which undermined the perfect harmony in nature and led to carnivores losing their previous vegetarian ways) is a test of one's faith in a creator God, then students have a very strong rationale for rejecting evolutionary ideas.

Moreover, although scientists will suggest that the case for natural selection-drawing upon a range of different lines of evidence from various branches of science-is overwhelming, the extent to which this vast evidence base, and the arguments that link it to the 
case for evolution, can be presented in high school biology classes is clearly limited. Many students in some communities will have more (and more regular) exposure to creationism advocates' arguments for why macro evolution-evolution at the level of main groups of organisms - has not been demonstrated, and their claims about the flaws and errors in the scientific case, than to the scientific grounds for accepting evolution. Evolution is one topic in part of school science. For some students, creationism is a creed reinforced weekly over many years. Both 'sides' (evolution deniers and champions) may accuse the other of selective use of evidence, misrepresentation, and self-delusion-leaving students to make a choice based on community membership and greater respect for one source of authority rather than the quality of the case from evidence.

\section{Science teaching as guiding not persuading}

Given this situation, some science educators would argue that teachers should welcome and value students' views and invite them to join a conversation where their potentially anti-evolutionary commitments are acknowledged and respectfully considered in the science classroom (Reiss 2008). This argument starts from the assumption that simply ignoring learners' ideas and setting about teaching them something that appears to contradict deeply held faith commitments is very unlikely to persuade students to accept evolution and rather risks alienating students from science and the teacher. After all, constructivist teaching approaches in less controversial topics suggest that it is important to elicit and explore students' ideas and to compare them with the scientific models (Driver and Oldham 1986) — and this can seem even more sensible when we are aware that we are dealing material that students will not only find counter-intuitive but perhaps objectionable. This argument may take the form that 'converting' students to the scientific view over the course of a few science lessons is not a feasible option, yet it may be possible to get them to at least appreciate the scientific view so that they understand what it is they are rejecting, and something of why many other intelligent and decent people find the arguments convincing. Perhaps that is a seed and a suitable starting point for possible later changes of thinking (cf. Long 2011), but even if not then perhaps understanding the gist of natural selection is a reasonable goal when bringing about acceptance of evolution is simply not feasible.

This might seem a compromise to many science educators, because it comes across as more suitable for humanities teaching than science. In the humanities and social sciences it is not unusual for teachers to present and explore alternative perspectives in class, without seeking to persuade students of the 'right' approach to adopt. The aim of such teaching may be to get students to appreciate different perspectives, and be able to compare them, and to appreciate their strengths and weaknesses - and also why the preference a person makes for a particular position often depends as much on their existing background commitments as inherent qualities of that position.

Our existing understandings and value systems necessarily colour how we make sense of any new ideas we meet. This was a point that Thomas Kuhn (1996) made based on his historical studies of what he called paradigm shifts in science: that even in 'objective' science we cannot evaluate ideas in a totally neutral way as we are always adopting the limited viewpoint(s) our particular existing understandings allow. As the anthropologist Clifford Geertz (1973/2000, p. 35) noted, people "unmodified by the customs of particular places do not in fact exist, have never existed, and most important, could not in the very 
nature of the case exist". It is the nature of being human, that we can only make sense of new experiences through the interpretative resources we have iteratively constructed up to that point; and that construction process will reflect the resources we can access in the particular intellectual environment in which we develop (Taber 2013b). Kuhn's account was descriptive not prescriptive-he was not criticising the scientific ideal of working towards objective knowledge, but pointing out that scientific consensus always occurs in a historical context and so inevitably is somewhat culturally relative. Kuhn was not seeking to have relativism admitted into science (as has sometimes been suggested), but simply acknowledging that it could never be fully excluded.

Science teaching, however, has not generally tended to offer students a range of perspectives on a topic in the way that some other disciplines inherently do. In science classes teachers usually present the current scientific consensus knowledge-or at least do their best to offer a teaching model of the scientific ideas that is suitable for the academic level of the students yet still true to the essence of the science. Many science teachers would consider that is challenging enough, and that considering alternative perspectives in science lessons would be a poor use of limited class-time, and could be potentially confusing for many students. Indeed asking students to make sense of alternative perspectives and appreciate how each may be preferred from some viable position is certainly more challenging for learners than simply telling them the version that scientists have come to accept as the best current way of thinking about some particular topic (e.g. Perry 1970). Teaching science as offering well-developed and evidenced, but uncertain, knowledge risks students - and younger learners, who tend to expect knowledge of the world to be definitive and factual, in particular-dismissing scientific accounts as little more than particular scientists' guesses or personal opinions about the world (Taber, Billingsley, Riga and Newdick 2015).

In the case of teaching evolution in some cultural contexts, however, simply presenting natural selection as the perspective to adopt will be resisted and risk alienation of students. Borgerding's study shows however that teachers who adopt the role of a guide to support cultural-border crossing may be able to help students learn about natural selection and the case for evolution in a less threatening way: not 'this is what you are meant to think', but rather 'this is how a lot of scientists who have spent time looking at the evidence think they can best explain features of the natural world'. Students may not wish to emigrate to the foreign territory they have been shown: but perhaps they will not find the visit too threatening, and possibly they will be more willing to visit again in the future. If that is a compromise on what many biology teachers would like to achieve, it seems a sensible and honourable one when the alternative may be to set up teaching about evolution as an invitation to accept or reject something which is contrary to students' core lifeworld commitments.

\section{Cultural border crossing should not be seen as a compromise but the model for science pedagogy}

Yet there is an alternative perspective here as well: one which does not see teacher-as-acultural-guide as a compromise on 'teacher-as-scientific-prosthelytiser', but rather sees teaching-as-persuading-students-of-the-science as being the compromise, and a rather poor one at that. Science, like the humanities and social sciences, has plenty of contention, and indeed the essence of science is not the learning of current consensus ideas, but the active 
work going on at the boundaries of knowledge where scientists do not yet agree on how best to conceptualise particular features of the natural world. Teaching which largely presents (in retrospect) consensus scientific models often divorced from the processes by which they became accepted gives a distorted view of the scientific enterprise as relatively straightforward application of logic leading to the scientific community adopting unproblematic 'scientific knowledge' (Taber 2011). This is both unauthentic and-compared to science itself_-dull.

In particular, teaching science as a 'rhetoric of conclusions' (Schwab 1962) misrepresents the nature of scientific knowledge. At one time scientists may have considered they were extracting 'truth' from nature through observation and experimentation (Pesic 1999). The tradition of natural theology was based on metaphysical commitments to the natural world as a record of the works of a creator God, who had created people in His own image - and so able to read the 'book of nature' (Taber 2013a). The notion of science as an objective process revealing eternal truths is no longer viable given much scholarship about the history and philosophy of science. So, for example, Karl Popper (1934/1959) argued that induction could not logically lead to definitive proofs, Thomas Kuhn (1996) suggested that all scientists were inherently biased by the conceptual frameworks they bring to a problem, and Imre Lakatos (1970) described how scientists regularly 'quarantined' inconvenient results and saw them as puzzles that could be ignored for the time being, rather than refutations of their ideas. It is now widely recognised that all scientific knowledge is conjectural in nature, and that all tests of hypotheses are actually tests of conjunctions of the focal idea plus various background assumptions and theories relating to the instrumentation of data collection and analysis (so that what a test refutes is not necessarily the explicit hypothesis itself). Theories are always underdetermined by data (that is, there is always another theory someone could construct which would also fit with the available evidence), and models have ranges of application. Even laws may not be as universal as once assumed if they might have themselves evolved along with the universe.

None of this undermines the value or utility of science, but it does mean that science teachers are teaching (at least in principle, somewhat) provisional knowledge, because science is always open to new evidence, and there is nothing we can be sure we understand so well that further evidence would not offer a better conceptualisation. Newton's mechanics was once assumed to be the scientific description of some important features of the way the universe is, until tests of the consequences of Einstein's conjecture about the invariance of the speed of light showed that Newton's mechanics was just a model which —although of wide application — would not always 'work'. That these flawed ideas were good enough to be used to get people to the moon and back safely only underlined how science can never assume it has reached final, ultimate, truth. This also showed how even though science can not be taken as offering absolute truth-it can still offer conceptual tools of immense power and value.

Our modern understanding of the nature of science, what might be labelled a postpositivist view of science, is of a powerful process that produces knowledge that is of great utility. In terms of the philosophical ideal of knowledge as true, justified, belief scientific 'knowledge' falls well short-it is never assumed to be true, it is only provisionally justified, and it needs to be entertained and considered rather than believed. If we wish science education to offer an authentic reflection of the nature of science then scientific ideas should not be presented as factual, and proved-but as theories, and models, as hypotheses which have survived repeated testing to date, but which are always kept open to further scrutiny. Some of these ideas have proved so good at representing nature that we might reasonably treat them as almost certain. Others may be better characterised as our current best guesses. 
We are well aware that many canonical scientific ideas only work up to a point - within a certain range of application or to a given level of approximation. There is no sense in asking which is the correct model of the atom, or which is the best theory of acidity-as the answer to these questions depends upon the particular purpose we have in mind. Even conceptual tools as useful in making sense of the natural world such as 'molecule' and 'species' fail to provide clear absolute discriminations under some conditions.

These characteristics and limitations are only flaws if we expect science to provide absolute and final truths. If however we see science as an on-going process of developing useful descriptions, characterisations, and models to inform our understanding of - and action in - the natural world, then science is highly successful. The provisional nature of scientific knowledge may even make science seem less arrogant, and perhaps seeing science as a dynamic enterprise will attract more students to consider careers in science. Presenting scientific ideas along the lines of 'we can usefully model' (the electron as a kind of wave...semiconductor properties in terms of bands of overlapping molecular orbitals...the relationship between different hominid species during human evolution) rather than 'this is how scientists have determined (i.e., believe) the world is' offers a more authentic reflection of the nature of scientific knowledge.

An attraction of an authentic representation of scientific knowledge in science education is a move away from teaching that many learners find frustrating where more advanced courses seem to contradict what they had worked hard to learn in earlier introductory classes. Appreciating that science is not about truths, but rather is about viable constructions of the world-ways of making sense of nature that are worth keeping in the conceptual toolbox because they are useful—would allow learners to appreciate, for example, a planetary model of the atom as just that, a model, and a definition of oxidation in terms of electron transfer as just one useful way of making sense of some types of reactions. If students are taught in this way then subsequent teaching of the atomic orbital concept has a better chance of not being simply assimilated into the previously learnt and established planetary atom and the notion of formal oxidation states need not be a threat to a hard-won understanding of redox in terms of electron transfer (Taber 2010). Readers will likely be able to add many further examples of their own.

\section{Science is not about belief}

In particular, the approach to teaching science discussed here avoids encouraging 'belief' in the science taught because belief is not an appropriate term for scientific commitment. Indeed openness to disbelief in scientific accounts of the world is a core commitment of science. One of the particular values considered to be central to the scientific enterprise is the ability to remain sceptical and potentially critical of all ideas-even those that have proved their usefulness to us time and again. This attitude is largely contrary to the natural attitude and the inherent biases of human cognition (Nickerson 1998). Even scientists can fall into what George Kelly (1958/1969, p. 85) called a "common pitfall of so-called objective thinking, the tendency to reify our constructs and treat them as if they were not constructs at all, but actually all the things that they were originally only intended to construe". Arguably, the self-critical faculty that holds all knowledge as conjectural and open to revision is one of the most useful things science education can seek to teach.

Teaching students to consider scientific ideas of high utility, yet not something to be believed, means adding an additional dimension to all scientific ideas taught (e.g. relating 
to the range of application, or extent of supporting evidence). As noted above, younger learners tend to more readily interpret the world in terms of absolute truths rather than ideas that may often be useful, but may not always apply (D. Kuhn 1999) — so even when teachers are quite clear in their own minds about the conjectural status of scientific knowledge this is unlikely to be communicated unless it is made explicit in teaching. Despite the challenge here, teaching this way has great potential advantages. So, for example, teachers will not need to get learners to stop believing that all chemical bonds are covalent or ionic (in order to teach about metallic bonds, or polar bonds) if students were encouraged not to believe that bonds are ionic or covalent in the first place. If science education is always approached as being about introducing useful concepts, models, and theories, then students can be taught, for example, some useful models of bonding as helpful conceptualisations, without learners considering they should take this as an absolute, proved and final description of nature.

\section{The teacher as intellectual tour guide in the light of the nature of personal knowledge}

One area of major research activity in science education has been the exploration of students' ideas about scientific topics (Duit 2009). Students have been said to have alternative frameworks or misconceptions, and to construct scientifically inappropriate conceptions of the world drawing upon implicit knowledge elements that channel the learner's interpretation of their observations and instruction. However, the research has also made it clear that describing learners' knowledge structures is difficult because thinking (which itself can only be indirectly observed when it is represented publicly by the thinker) is always in flux and is often manifold. Research shows that 'holding' or 'having' an alternative conceptual framework of a topic (in the sense of such ideas being elicited in research) does not imply not also having an understanding of the canonical concept - and vice versa. Human knowledge often tends to comprise a range of alternative constructions which are being explored and tested against experience-and if this was not the case conceptual change would be even more difficult to achieve. When exploring student thinking about science topics the researcher has to be aware of the fluid and manifold nature of thinking about many topics and consider the student's knowledge as "the range of notions under current consideration as possibly reflecting some aspect of how the world is" (Taber 2013b, p. 179).

From this perspective Aikenhead's notion of cultural border-crossing can be seen to a useful metaphor for science teaching-and not just when the science may offend for cultural reasons. Learning that according to science fungi are not plants; that insects count as animals but that spiders do not count as insects; that heat and temperature are quite distinct; that the earth is not closer to the sun in Summer; that many safe and healthy foods contain acids; and also that humans are considered to have evolved from something more like a bacterium, may all seem somewhat strange and 'other' to many students. Borgerding's teacher-as-cultural-tour-guide offered safe passage into the land of evolutionary thinking allowing students to safely explore the landscape as a valued visitor without being expected to commit to emigration or even being hard-sold a kind of intellectual time-share in the alien land. Arguably there is much in the science curriculum which would benefit from this approach because so many scientific accounts are ontologically strange to many learners (Chi 1992), even when the scientific models and theories only seem to challenge the students' common sense and not their sense of common decency. 
If we take seriously the post-positivist view of scientific knowledge and seek to offer authentic science education, and if we acknowledge the research showing that students' knowledge structures are often manifold and in flux, then seeing science teaching in terms of seeking to 'replace' students' alternative conceptions with scientific truths makes little sense. Science teaching should never be about getting students to believe the scientific accounts, but should always be about inviting students to explore scientific ideas sufficiently to see why they are considered viable and useful ways of construing the natural world. It is not the job of the science teacher to persuade students to believe in natural selection, but just to understand it well enough to appreciate why many scientists consider it the best available theory based on a range of empirical evidence.

If science is not about belief, then having learners come out of science lessons believing in evolution, or for that matter believing that magnetic fields lines are more concentrated near the poles of a magnet, or believing that energy is always conserved, or believing that acidic solutions contain solvated hydrogen ions, misses the point. Science education should help students understand scientific ideas, and appreciate why these ideas are found useful, and something of their status (for example when they have a limited range of application). Once students can understand the scientific ideas then they become available as possible ways of thinking about the world, and perhaps as notions under current consideration as useful (but not final) accounts of how the world is. This allows them to explore the value of these ideas in the future, and given sufficient familiarity and experience with them a learner may in time come to freely commit to them as valuable conceptual tools. Perhaps they will even come to believe that the scientific model or theory is the best way of understanding some aspect of the natural world. Hopefully, however, they will recognise that judgement is somewhat provisional, and they will not move on to mistake the model or theory for a final account of how the world really is. Belief in science should be epistemological not ontological: a belief in the scientific approach as the best way to develop viable understandings of the natural world. Ultimately in the case of natural selection such an approach may do more to lead those with strong cultural rationale for rejecting evolution as an account of the world to at least consider it as an alternative perspective worth thinking about, than attempts to make them change their mind with sheer force of argument. However, even if the teacher-as-cultural-tour-guide is not successful in teaching evolution, she will at least offer a more authentic glimpse of the nature of scientific knowledge.

Open Access This article is distributed under the terms of the Creative Commons Attribution 4.0 International License (http://creativecommons.org/licenses/by/4.0/), which permits unrestricted use, distribution, and reproduction in any medium, provided you give appropriate credit to the original author(s) and the source, provide a link to the Creative Commons license, and indicate if changes were made.

\section{References}

Aikenhead, G. S. (1996). Science education: Border crossing into the subculture of science. Studies in Science Education, 27, 1-52.

Allen, N. J., \& Crawley, F. E. (1998). Voices from the bridge: Worldview conflicts of Kickapoo students of science. Journal of Research in Science Teaching, 35, 111-132. doi:10.1002/(SICI)10982736(199802)35:2<111:AID-TEA3>3.0.CO;2-V

Chi, M. T. H. (1992). Conceptual change within and across ontological categories: Examples from learning and discovery in science. In R. N. Giere (Ed.), Cognitive models in science (Vol. XV, pp. 129-186). Minneapolis: University of Minnesota Press.

Dobzhansky, T. (1973). Nothing in biology makes sense except in the light of evolution. The American Biology Teacher, 35, 125-129. 
Driver, R., \& Oldham, V. (1986). A constructivist approach to curriculum development in science. Studies in Science Education, 13, 105-122.

Duit, R. (2009). Bibliography-Students' and teachers' conceptions and science education. Kiel: IPN Leibniz Institute for Science and Mathematics Education.

Geertz, C. (1973/2000). The impact of the concept of culture on the concept of man. In The interpretation of cultures: Selected essays (pp. 33-54). New York: Basic Books.

Kelly, G. (1958/1969). Man's construction of his alternatives. In B. Maher (Ed.), Clinical psychology and personality: The selected papers of George Kelly (pp. 66-93). New York: Wiley.

Kuhn, T. S. (1996). The structure of scientific revolutions (3rd ed.). Chicago: University of Chicago.

Kuhn, D. (1999). A developmental model of critical thinking. Educational Researcher, 28, 16-46.

Lakatos, I. (1970). Falsification and the methodology of scientific research programmes. In I. Lakatos \& A. Musgrove (Eds.), Criticism and the growth of knowledge (pp. 91-196). Cambridge: Cambridge University Press.

Long, D. E. (2011). Evolution and religion in American education: An ethnography. Dordrecht: Springer.

Morris, H. M. (2000). The Long war against God: The history and impact of the creation/evolution conflict. Green Forest: Master Books.

National Science Teachers Association. (2013). NSTA Position Statement: The Teaching of Evolution. Retrieved April 8, 2013, from http://www.nsta.org/about/positions/evolution.aspxacce

Nickerson, R. S. (1998). Confirmation bias: A ubiquitous phenomenon in many guises. Review of General Psychology, 2, 175-220.

Perry, W. G. (1970). Forms of intellectual and ethical development in the college years: A scheme. New York: Holt, Rinehart \& Winston.

Pesic, P. (1999). Wrestling with Proteus: Francis Bacon and the "Torture" of nature. Isis, 90, 81-94.

Popper, K. R. (1934/1959). The logic of scientific discovery. London: Hutchinson.

Reiss, M. J. (2008). Should science educators deal with the science/religion issue? Studies in Science Education, 44(2), 157-186. doi:10.1080/03057260802264214

Schwab, J. J. (1962). The teaching of science as enquiry (The Inglis Lecture, 1961). In J. J. Schwab \& P. F. Brandwein (Eds.), The teaching of science. Cambridge: Harvard Univewrsity Press.

Solomon, J. (1992). Getting to know about energy —In school and society. London: Falmer Press.

Taber, K. S. (2009). Progressing science education: Constructing the scientific research programme into the contingent nature of learning science. Dordrecht: Springer.

Taber, K. S. (2010). Straw men and false dichotomies: Overcoming philosophical confusion in chemical education. Journal of Chemical Education, 87, 552-558. doi:10.1021/ed8001623

Taber, K. S. (2011). The natures of scientific thinking: Creativity as the handmaiden to logic in the development of public and personal knowledge. In M. S. Khine (Ed.), Advances in the nature of science research-Concepts and methodologies (pp. 51-74). Dordrecht: Springer.

Taber, K. S. (2013a). Conceptual frameworks, metaphysical commitments and worldviews: The challenge of reflecting the relationships between science and religion in science education. In N. Mansour \& R. Wegerif (Eds.), Science education for diversity: Theory and practice (pp. 151-177). Dordrecht: Springer.

Taber, K. S. (2013b). Modelling learners and learning in science education: Developing representations of concepts, conceptual structure and conceptual change to inform teaching and research. Dordrecht: Springer.

Taber, K. S., Billingsley, B., Riga, F., \& Newdick, H. (2015). English secondary students' thinking about the status of scientific theories: Consistent, comprehensive, coherent and extensively evidenced explanations of aspects of the natural world-Or just 'an idea someone has'. The Curriculum Journal, 26, 370-403. doi:10.1080/09585176.2015.1043926

Thagard, P. (1992). Conceptual revolutions. Oxford: Princeton University Press.

Keith S. Taber is Professor of Science Education at the University of Cambridge where he chairs the Science, Technology and Mathematics Education academic group. He is especially interested in how students understand scientific concepts and the nature of science. His most recent book is Student Thinking and Learning in Science: Perspectives on the nature and development of learners' ideas (Routledge). He is editor of the journal Chemistry Education Research and Practice and book reviews editor of the journal Studies in Science Education. 